\title{
Parts of the Whole: The Educational Sieve
}

\section{Dorothy Wallace}

Dartmouth College, dorothy.wallace@dartmouth.edu

\section{Recommended Citation}

Wallace, Dorothy. "Parts of the Whole: The Educational Sieve." Numeracy 6, Iss. 2 (2013): Article 13. DOI: http://dx.doi.org/10.5038/1936-4660.6.2.13 


\title{
Parts of the Whole: The Educational Sieve
}

\begin{abstract}
This essay argues that the structure of course prerequisites affects retention of students in a course of study. The same argument suggests that the structure of degree requirements, including quantitative reasoning courses, affects retention in college. In particular, the same set of courses required in a rigid sequence will cause more students to exit the program early than if the same courses were offered in a flexible order.
\end{abstract}

\section{Keywords}

education research, mathematics education, quantitative literacy, quantitative reasoning, numeracy

Creative Commons License

(c) (i) (9)

This work is licensed under a Creative Commons Attribution-Noncommercial 4.0 License

\section{Cover Page Footnote}

Dorothy Wallace is a professor of mathematics at Dartmouth. She was 2000 New Hampshire CASE Professor of the Year, and the lead PI of the seminal NSF project, Mathematics Across the Curriculum. She recently finished a text in mathematical biology for first-year students, "Situated Complexity." She was a charter board member of the National Numeracy Network and is now co-editor of this journal. 


\section{Parts Of The Whole A Column by $\mathrm{D}$. Wallace}

The problem of how best to improve the numeracy of a society is a thorny one, embracing the learning process of a single student but rising in scale to include the management and alteration of an entire system of education. With the issue of quantitative literacy always in mind, this column considers various aspects of the systemic workings of education, the forces acting on classrooms, teachers and students, and mechanisms of both stasis and change.

\section{The Educational Sieve}

If the ability to produce a population with sufficient knowledge dispersion rests on a repertoire of prerequisite-free courses, the ability to produce sufficient scientists and mathematicians rests on the structure of the major and the incentives to completing it. A common perception of science faculty is that students tend to transfer out of the science and math majors more frequently than they move into them. Even a college that admits a class where half are planning to major in these subjects is unlikely to have half in them at graduation. Part of this is surely due to the difficulty of these subjects. Some of this effect may stem from a structural problem however, which is considered here. In particular, the addition of quantitative reasoning requirements and courses has a direct effect on the structure of course requirements, which may have unintended consequences for the recruitment of students into some subject areas.

In Figure 1 are two diagrams. Both represent course sequences for different major fields. On the left is a major with a specific sequence of entry courses that must be taken in a particular order. On the right is a major with a much more flexible way to arrange course sequences. Both of these diagrams represent past structures of actual majors at Dartmouth. The major corresponding to the right hand diagram had about ten

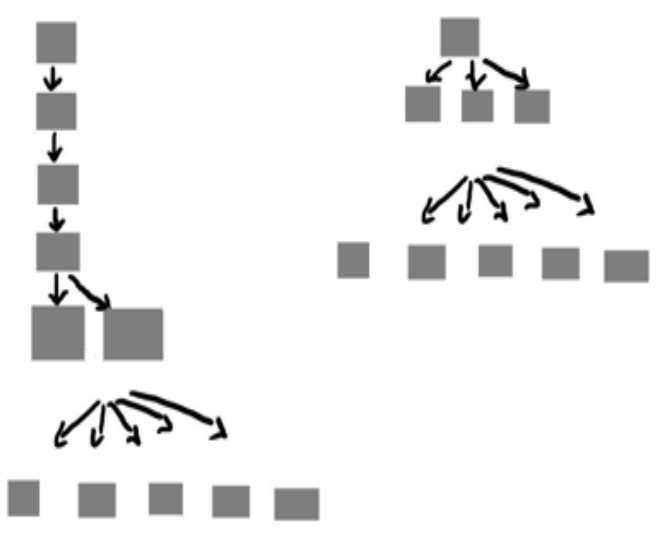

Figure 1: Prerequisite structures for two majors 
times as many students in it as the one on the left, even though the graduates of both majors were taking similar jobs upon graduation. Without knowing anything about the difficulty of these majors, I would argue that we would expect more people to major in the subject represented on the right, based only on the requirement structure.

Suppose a group of students complete the first course in the left-hand sequence. A certain proportion of them will look at the next required course and decide not to pursue the major. Some will take the second course and then look down the series at the third and quit. At every stage in the process, a certain number of students will look down the line and make the decision not to continue, even if there is some course near the bottom of the diagram that looks interesting to them.

Now consider students in the right hand sequence. After completing just one course, they have many options to choose from for the next course. After completing a second tier course they may take any of those remaining. There is a higher probability that a given student will stay in the sequence, even if there are some topics that student doesn't like as well. At every stage in the process, a higher number of students will be retained in the sequence, resulting in far more majors than we would expect on the left.

I am making a mathematical argument here. Let us say that there is a probability of $10 \%$ that any given student will not like the looks of a particular course or will do poorly in it and will choose to terminate the major at that point, and that these probabilities are independent. By the laws of probability over a third of the students will have exited the left hand sequence of four courses before reaching the branch point. On the right, the student has three choices after the first course, giving a 99.9\% chance of staying in the sequence after the first course. Then the student has seven courses from which to choose, then six. At the end of four decisions there is still an $89.9 \%$ chance the student is still in the major, with most of the fallout being from the decision to take the first prerequisite course in the sequence. If the first course in the sequence is straightforward and not discouraging, then the difference between the two structures becomes even more pronounced.

The right hand structure offers the student added flexibility, allowing him or her to take multiple classes in the major, early or late. A student can easily move into this major, whereas a late start will make it difficult to complete the structure on the left. Even if there were no difference in the difficulty of these two tracks, we would expect more people moving from the left track into the right than vice versa. For students hoping to work such things as foreign study or research experience into their college years, the right hand structure offers a much better frame for such extra adventures. 


\section{A Filter, Not a Pump}

The left hand structure above is a very effective sieve that guarantees fewer people stay in the major at every stage of the process. Some years ago the National Science Foundation sponsored a large initiative to improve introductory calculus courses. These courses typically appear as the first course in several sieves such as the one on the left above. Math, physics, engineering and chemistry all have a series of calculus prerequisites. The slogan that came out of the calculus initiative was telling: "Calculus, a pump, not a filter." The structure illustrated in the left hand diagram displays the futility of the solution proposed by the Foundation. No matter how good a single course could be made, the structure it sits in is a sieve. To improve retention in a major with such a structure requires that every single course be a pump, and a good one, too. Even so, no one will be able to move into that major after a certain point in his or her college career because it will take too long to satisfy the linear prerequisite sequence. Yet students will always be able to leave.

Most linear structures like the ones on the left are mere cultural artifacts and do not really reflect in what order it is possible to learn material. Many of these structures, like the one for the mathematics major, are in place for the very purpose of creating a body of students with similar background knowledge. The structure comes from a desire to reduce variation among the students. This strategy is appropriate at the K-12 level, but misguided at the college level. The argument made here suggests that the efforts to produce a homogeneous population of science or math majors in order to advance them quickly has had the structural effect of removing many from the sequence entirely.

Any approach to a systemic improvement on the number of majors in any given area must take the overall structure of requirements into account. This recommendation serves not only a single institution, but can also guide funding efforts and statewide coordination of offerings. It should inform discussions among college administrators and among faculty of any given department. Those who fund educational research should make the analysis of structural impediments a priority. Those who fund "systemic initiatives" should make sure their grantees understand the effects of the system in the first place. A project that merely influences every part of the system is not necessarily addressing any underlying "systemic" causes.

The observations above have implications for quantitative reasoning requirements and courses at the college level. Even if such a course is a universal requirement, students are likely to perceive it as being in the math/science universe. As such, it may become one of the decision points for students considering a major in the sciences or math. One unintended consequence of the $\mathrm{QR}$ requirement may be even fewer students going into those majors. If the QR topics lean towards the social sciences or personal finance, this may actually be 
better for recruitment into the sciences. In science majors where quantitative topics appear throughout, incorporating the explicit teaching of relevant mathematics into all courses may be a better strategy than creating a prerequisite that attempts to do it all and in the process becomes a critical decision point for students. Finally, it is worth pointing out that, for weaker students, prerequisites are decision points about staying in college at all. Requiring a linear sequence of (quantitative or other) prerequisites for college itself creates the ultimate sieve. No matter how good these courses are, the structure in which they sit works against students staying in the system. 